\title{
Cutting the cake: government spending plans for $1986-9$
}

\author{
MARK McCARTHY
}

This year's public expenditure White Paper is larger, more detailed, and more expensive than any previously. ${ }^{1}$ Volume 1 is a slim overview of government spending; volume 2 gives each department's spending in more detail, as well as some information on the services provided. The White Paper is thus the equivalent of a company annual report, with all the nation as shareholders. How do the prospects look?

The spring budget is the endpoint of a series of close negotiations between the Treasury and government departments during the previous 12 months. An autumn statement (in November) gives the broad results of the annual review of public spending, and the expenditure White Paper (nowadays issued in January) defines the plans for the forthcoming financial year and projections for the future. Revisions of spending and indications of revenue from taxation and borrowing are finally incorporated in the budget.

\section{Overall spending plans}

The Conservative government, in both the 1979 and 1983 party election manifestoes, has been committed to make tax cuts and to reduce public spending. By this criterion its record so far has been weak. Public spending as a proportion of the economy (gross domestic product) rose from $43.5 \%$ in 1979 to $46.5 \%$ in 1983 and now remains at $44.5 \%$; and spending rose in real terms - that is, taking inflation into account-each year up to 1985 .

There are two reasons for these trends. Firstly, the economy declined sharply in the early 1980s and is only now recovering: this has reduced the denominator on which the public spending proportion is calculated. Secondly, the biggest single component of public spending, social security, continues to rise, thus pushing up the absolute expenditure (the numerator in the proportion). This rise is partly demographic-the increasing number of old age pensioners-but also reflects the consequences of the economic slump, in benefits to the unemployed and their dependants.

Over the next three years the government proposes to keep total public expenditure at the present level, in real terms. With an expanding economy public sector spending should at last fall as a proportion of the national economy. Apart from taxes the government hopes to extend its income through more privatisation, selling off national assets such as the water authorities and the valuable land that they own. This is a gamble, hence the estimates also have large reserves built into them in case this policy should fail. But if growth in the economy continues, unemployment does not rise too much, and the price of North Sea oil does not fall further there could be room for modest tax cuts in a future budget.

Yet over the past seven years there have been marked alterations in the internal distribution of public spending. Housing, education, the nationalised industries, and energy have all taken substantial cuts, while social security, defence, and health and personal social services have increased. Figure 1 shows the percentage shares of public spending by function in the last year of the Labour government and the current financial year and also the government's projected spending.

A social survey in 1984 showed that one in three people would accept an increase in taxes, if the money was spent on health, education, and social benefits, and only $9 \%$ would like a reduction. ${ }^{2}$ Similarly, whereas $29 \%$ of people interviewed thought that levels of

Department of Community Medicine, University College London, London WC1E 6EA

MARK MCCARTHY, MRCP, MFCM, senior lecturer in community medicine

\section{Objectives for the NHS 1986-9}

To meet the greater demands for services for the growing number of elderly people, an estimated increase of $1 \%$ in $1986-7$, falling to $0.8 \%$ in $1988-9$.

To take full advantage of advances in medical technology and to remedy shortfalls in certain treatment areas-for example, renal services.

To combat social problems such as drug misuse.

To promote preventive health care.

To continue to improve primary care and community health and social services for people who do not require continuing hospital care.

To improve the service's response to the consumer.

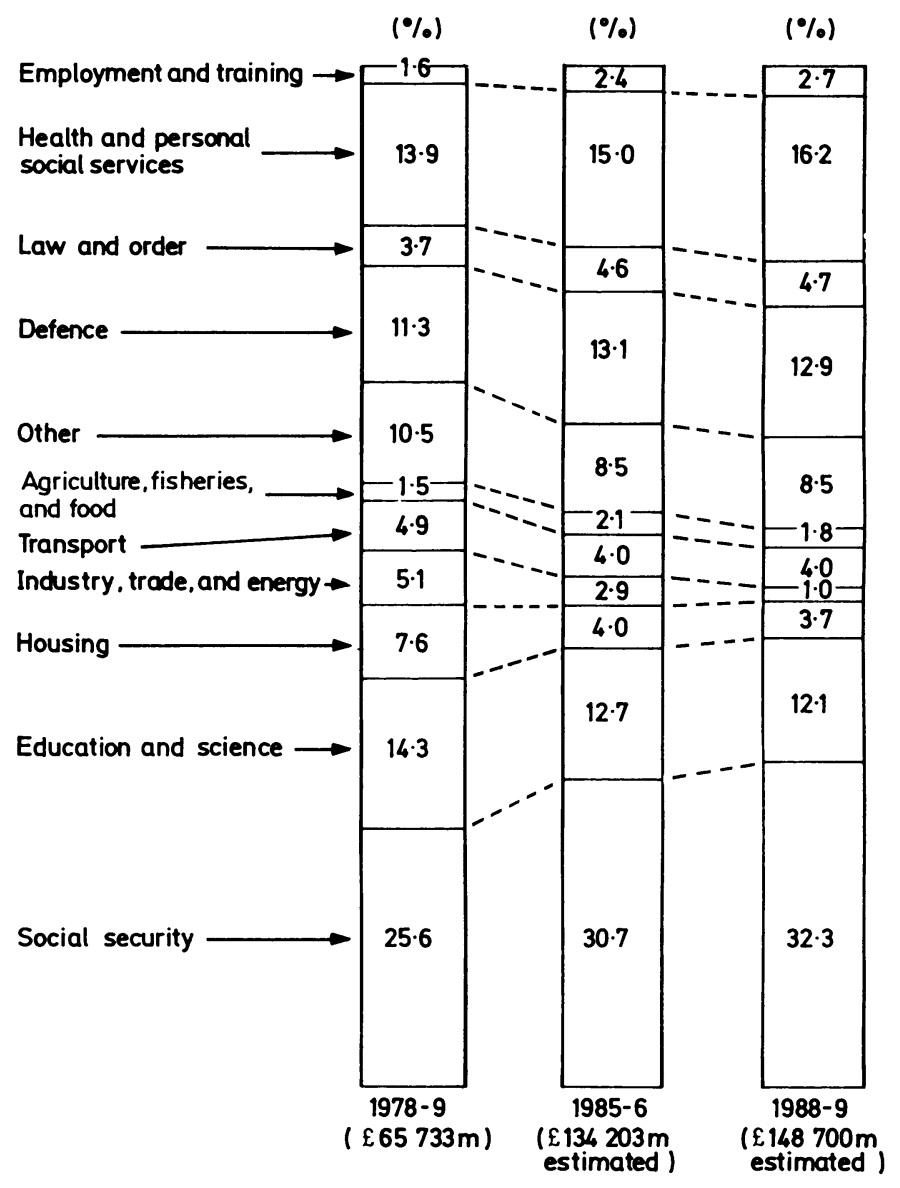

FIG 1-Public spending in UK by function 1978-9, 1985-6, 1988-9. 
taxation for people with high incomes were too high, $44 \%$ thought that middle incomes were taxed too highly, and $79 \%$ thought that low incomes were taxed too highly. The inference is that there would be most support for more progressive income taxation, especially if it were used for socially favoured spending.

It is interesting, therefore, to look at the projections for departmental spending in the next three years, the period expected to lead up to the next election. The figures show a continued expansion for health services, at a faster rate than before, an almost static budget for the prison service and the police, and a reduction for defence. These proposals suggest a recognition of the mood of the country, although they are also a $U$ turn in government policy.

A new trend can also be discerned in the distribution of National Health Service cash between the four constituent countries of the United Kingdom. Scotland and Northern Ireland have historically received a larger share of the NHS budget than might be expected on a simple per caput calculation or adjusted according to a RAWP formula. ${ }^{3}$ In recent years Wales, which was comparatively underfunded, has improved its position. Table I shows that the average increases for all four countries are higher than the predicted inflation. But Scotland and Northern Ireland are now expected to grow more slowly than both England and Wales. The historic inequalities between the countries should reduce if this course is pursued.

TABLE I-Percentage increases in NHS expenditure 1983-6 and 1986-9

\begin{tabular}{|c|c|c|c|c|}
\hline & \multirow{2}{*}{$\begin{array}{l}\text { Actual (estimated } \\
\text { average) } \\
1983-4 \text { to } 1985-6\end{array}$} & \multicolumn{3}{|c|}{ Projected } \\
\hline & & $1986-7$ & $1987-8$ & $1988-9$ \\
\hline England & $6 \cdot 8$ & $6 \cdot 2$ & $4 \cdot 1$ & $3 \cdot 7$ \\
\hline Wales & $7 \cdot 1$ & $7 \cdot 0$ & $4 \cdot 0$ & $4 \cdot 3$ \\
\hline Scotland & $7 \cdot 0$ & $5 \cdot 7$ & $3 \cdot 6$ & $3 \cdot 6$ \\
\hline Northern Ireland & $6 \cdot 3$ & $5 \cdot 4$ & $4 \cdot 0$ & $4 \cdot 3$ \\
\hline \multirow{2}{*}{$\begin{array}{l}\text { Inflation (gross domestic } \\
\text { product) }\end{array}$} & & & & \\
\hline & $4 \cdot 7$ & $4 \cdot 5$ & $3 \cdot 5$ & $3 \cdot 0$ \\
\hline
\end{tabular}

\section{Health and personal social services spending}

Real spending on health and personal social services has increased over the past seven years, but there is a debate as to exactly how much it has grown. The confusion was examined recently by Bosanquet. ${ }^{4}$ Total spending on the NHS, as cash, is easily identified from the government accounts. Adjustments for inflation, however, can lead to different answers. The gross domestic product deflator, preferred by the government, is based on the resource costs to the whole economy-including changes in international prices and improvements in productivity through automation. This index yields an estimated $20 \%$ real improvement in resources available to the NHS since 1979. On the other hand, adjusting the total by an index that takes into account only movements in NHS pay and prices gives a much lower figure-an $8 \%$ improvement. This is closer to what people working within the service believe to be true.

How has expenditure been moved between sectors of the NHS? The period from 1970 to 1984 saw a shift in spending towards family practitioner services (from $19 \cdot 3 \%$ to $22 \cdot 0 \%$, mainly owing to an increasing drug bill); increases in services for elderly, physically handicapped, and mentally handicapped people (from $16.5 \%$ to $20.2 \%$ together); and a fall in acute services and care for children and the mentally ill (from $59 \cdot 7 \%$ to $49 \cdot 7 \%$ ). These changes, however, happened mainly in the first decade. While Conservative ministers continued to express support for the "priority" sectors, the spending patterns stayed roughly level in the 'eighties.

On the other hand, there have been changes in money allocated within sectors over the past seven years. The hospitals have increased their spending on direct patient care and reduced spending (relatively) on administration and support. Table II shows the increases in expenditure on staff and a fall in spending on provisions. This is contrary to the myth, held by many at ward level, that staff numbers are being reduced while administration is expanding. Hospital and community health services administration together have, in fact, been reduced substantially, by $13 \%$ between 1979 and 1984 , and now represent only $4.5 \%$ of the total hospital and community health services budget.

TABLE II-NHS hospitals services revenue $1978-9$ to $1983-4 .{ }^{4}$ Values are £m(\%)

\begin{tabular}{lrr}
\hline & $1978-9$ & $1983-4$ \\
\hline Medical and dental staff & $326(9 \cdot 0)$ & $725(10 \cdot 4)$ \\
Nursing staff & $1183(32 \cdot 5)$ & $2448(34 \cdot 9)$ \\
Medical and surgical supplies & $333(9 \cdot 1)$ & $698(10 \cdot 0)$ \\
Diagnostic and service departments & $318(8 \cdot 7)$ & $658(9 \cdot 4)$ \\
\hline Subtotal & $2160(59 \cdot 5)$ & $4529(63 \cdot 7)$ \\
\hline Administration, records, and training & $279(7 \cdot 7)$ & $548(7 \cdot 8)$ \\
Provisions & $729(20 \cdot 0)$ & $1099(15 \cdot 7)$ \\
Estate and other & $472(13 \cdot 0)$ & $889(12 \cdot 7)$ \\
\hline Total & $3641(100)$ & $7009(99 \cdot 9)$ \\
\hline
\end{tabular}

The level of qualification of nursing staff has also improved in all but two of the 14 English regions. The greatest improvement has been in the South Western region, with an increase in nursing hours per week of $13 \cdot 8 \%$ overall and for sisters and staff nurses of $11 \%$ and $22 \%$, respectively. ${ }^{4}$ Four of the six regions most squeezed by the effects of the Resource Allocation Working Party (RAWP)Mersey, Oxford, and the Thames regions-also improved their levels of qualified staff. This was especially noticeable in geriatric services, but all sectors, including acute care, have benefited.

The government's projections for spending by the Department of Health and Social Security over the next three years are given only as cash totals. Six service objectives are described (see box), reflecting varied social and political demands. Ever since Barbara Castle was Secretary of State for Social Services, the demographic pressure of elderly people has been recognised by the Treasury as a legitimate argument for extra resources. (The same logic, because of the lower birth rate in the 1970s, has worked against education, but the suggestion on these grounds that maternity services should receive less NHS money was fought off by the obstetricians. ${ }^{5}$ )

The White Paper estimates the effect of demographic changes as $1 \%$ on the hospital and community health services. In fact, even during the past seven years of slower total NHS growth, geriatric service inpatients have increased by an annual average of $6 \cdot 7 \%$ and outpatient attendances by $5 \cdot 1 \%$. As the acute specialties have also been expanding it is clear that the NHS has been improving the care of elderly people well beyond the demographic trends.

Geriatric services, however, work closely with local authority social services. Day care places for elderly people have also increased since 1979, at 3.5\% per annum, and the number of home help staff, who bear the brunt of domiciliary care, has increased by $2 \cdot 1 \%$ per annum. Thus the most worrying feature of the White Paper expenditure projections is that spending on personal social services is to be held level, in cash terms, from 1986-7. This means a real cut of $3-5 \%$ per annum, the exact level depending on the rate of inflation.

This year's White Paper is the first ever to propose a cut in social services spending. It is glossed over by the comment that "The annual increase (for personal social services) for 1986-87 is greater than the average increase for all local authority services." But the government has no absolute control over local authority spending, and, as it is seeking cuts in the total budgets, it cannot be surprised if social services are also cut. The implications are serious. Not only will NHS hospital services be overloaded if there is a reduction in domiciliary support for elderly people, but other programmes of community care, especially for mentally handicapped people, could also come to a standstill. These issues deserve wide debate.

It is also interesting to look at the distribution of spending in the White Paper. Scraps of extra money have been identified for services to drug misusers and patients suffering from AIDS. High technology care continues to receive special attention, with mention of coronary bypass, renal failure, and bone marrow transplants. A 
third heart transplant centre, in the north of England, is also to be furded. There is, however, a welcome emphasis on family practitioner services in the later years (figure 2). Apart from the development of computerised cervical cytology recall, improvement of the general administration of family practitioner committees requires greater investment. The long promised Green Paper on primary care should focus clearly on this issue.

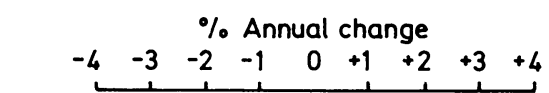

$1986-7$
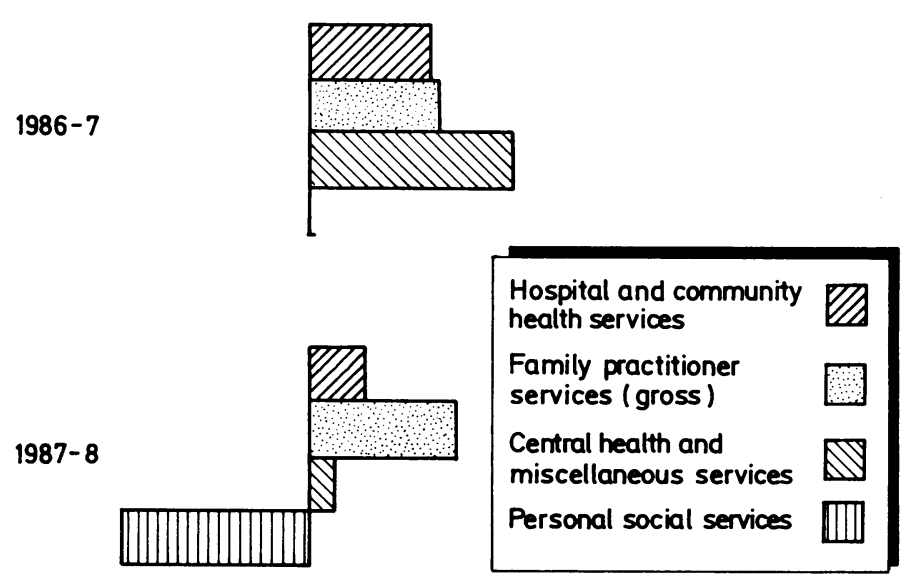

$1988-9$

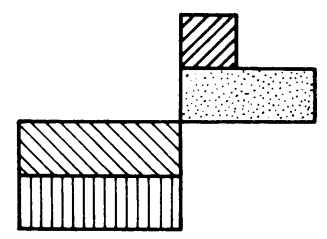

FIG 2-Planned changes in health and personal social services spending by sector after discounting inflation 1986-7 to 1988-9.

\section{Other sectors}

The White Paper offers the chance for parliament to consider government spending as a whole and also by individual departments. Other sectors of the economy have implications for health care. Of most immediate concern is the Department of Education and Science. Local authority spending is to be held steady in cash terms, with no increase for inflation. This, therefore, represents a cut of around $3-5 \%$ cumulatively each year, irrespective of higher salaries that might be given to the teachers. While numbers of secondary school children will fall during the three years, primary school pupil numbers will rise. Cuts in adult education are also envisaged; these may exacerbate the problems of developing community care -for example, for mentally handicapped people.

Universities are to receive cash increases of about half the projected rate of inflation, thus also experiencing cuts over and above the substantial reductions of the past five years. Although medical schools have been relatively protected in the past and medicine has more generous student to staff ratios than other subjects, this may not continue. Funding for the research councils has been kept above inflation levels for 1986-7 but is to be cut in subsequent years.

The other sector of most relevance to health care is social security. This is the largest single sector of the budget and continues to grow inexorably. At present 12 million children receive child benefit and 9.5 million people receive retirement pensions. But, in cash terms, half of the total is paid to elderly people, a group which is increasing in the population in relative and absolute terms. The government has recently published a White Paper on social security, ${ }^{6}$ and it hopes to reduce the call on public spending in the future.

The government's expenditure plans do not meet the demographic trends and would imply some real reduction in benefits. But the extent that benefits are raised is a sensitive political issue, and in previous years cuts have been converted into improvements in the heat of public scrutiny. Nevertheless, several of the proposed changes in the structure of social security need to be watched. While the state earnings related pension scheme (SERPS) is to be retained, the government plans to recalculate it to give lower benefits, and employees will be encouraged to opt out into private schemes. The effect, whether on larger or smaller pensions, will be long term.

The government's proposal to "simplify" housing benefit also means actual reductions in the number of people eligible, and the change to low income support through direct subsidy in the wage packet could encourage more widespread lower incomes. New approaches to community care depend crucially on generous assessment of supplementary benefit for disabled people.' A limit on supplementary benefit payments could delay NHS programmes to close the larger institutions.

But while the White Paper describes plans for governmen expenditure, it is silent about the other area of Treasury responsibility-taxes. Last year the Treasury gave the following evidence to the House of Lords Select Committee on the European Community, which was reviewing cooperation on health issues: "There are many economic, financial and fiscal policies in which the Treasury has an interest and which have an impact on health care. Customs and Excise are submitting evidence to the subcommittee on one of the most obvious, the taxation of cigarettes and alcohol. But there are others. In determining its policies ... the government will continue to take account of the effects on health care; it is unlikely however that this will be the most important consideration." "Just so.

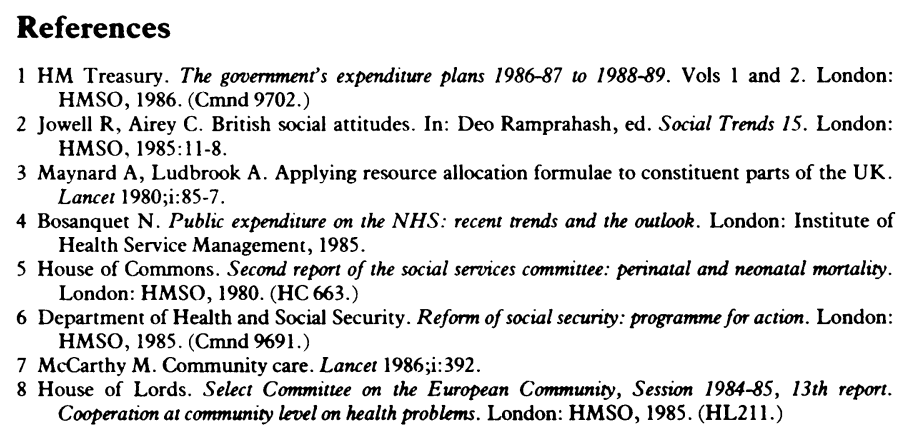

\section{THIRTY YEARS AGO}

\section{Emergency Call Service}

SIR, - When I was house-surgeon at Poplar Hospital in my youth we dined at a lovely old table bequeathed to the M.O.s. A brass plate in the centre informed us that around this table in bygone days a distinguished physician and a few good friends met to try to put an end to human slavery. At this period it was regarded as a forlorn hope, but they eventually cleaned up the world of this inhumanity of man to man.

It seems remarkable that in 1956, when progress is everywhere, we as a profession are standing still on the human side. Every other worker is having more leisure, but we seem to belong to a profession whose religion consists in worship of the patient and consequent neglect of the duty we owe our families. Does anyone ever give us the slightest consideration? As an old doctor I would say "Very few." It is not unexpected that when some progressive enlightened idea comes along it will be opposed, for you, may always expect that. I am delighted that London has this emergency service so that single-handed doctors may have time for living and some of the joys of life. Especially does this apply to the doctor's wife. It seems queer that we seem so shackled to our old shackles. The State medical service is a bogy we can ignore. We should lose very little and gain a lot. The capital expenditure would be enormous, and the State would be unlikely to embark on an expensive system when it has the present system at an economic cost.

Opposition from the G.M.S. Committee may be expected. Its members usually belong to a partnership and the shoe does not pinch them. I wish the E.C.S. every success.-I am, etc.,

Albert E. Nicholls 